\title{
Working Memory and Verbal Memory's Relationship to Discourse Comprehension in Patients with Amnestic Mild Cognitive Impairment and with Alzheimer's Disease
}

\author{
Hyunjoo Choi \\ Department of Communication Disorders, Korea Nazarene University, Cheonan, Korea
}

Correspondence: Hyunjoo Choi, PhD Department of Communication Disorders, Korea Nazarene University, 48 Wolbong-ro, Seobuk-gu, Cheonan 31172, Korea Tel: +82-41-570-1677

Fax: +82-41-570-7846

E-mail: hjchoi@kornu.ac.kr

Received: January 17, 2016

Revised: April 29, 2016

Accepted: May 1, 2016

This work was supported by Korea Nazarene University Research Grants 2016.

\begin{abstract}
Objectives: Impairment of story comprehension ability is known to appear in the early stages of Alzheimer's disease (EAD). The main purpose of this study was to identify performance differences in story comprehension among healthy elderly adults, patients with amnestic mild cognitive impairment (aMCl), and patients in EAD in order to see working memory and verbal memory's relationship to discourse comprehension in the three groups. Methods: Thirty healthy elderly adults, 30 patients with $\mathrm{aMCl}$, and 30 patients with $\mathrm{EAD}$ participated in this study. They took part in a story comprehension task, a working memory test (forward/backward Digit Span Test) and a verbal memory test (Seoul Verbal Learning Test [SVLT]). Results: The results were as follows. First, there were significant differences in story comprehension performance among all groups (healthy elderly $>\mathrm{aMCl}>\mathrm{EAD}$ ). Second, there was a significant correlation between story comprehension performance, scores of the backward Digit Span Test, and scores of the SVLT in healthy elderly adults and the EAD group. Third, there was only significant correlation between story comprehension performance and delayed recall scores of SVLT in the aMCI group. Conclusion: These results suggest that impairment of story comprehension ability appear in the aMCl stage and that working memory and verbal memory's relationship to discourse comprehension differ in the progression of AD.
\end{abstract}

Keywords: Amnestic-mild cognitive impairment, Alzheimer's disease, Story comprehension, Working memory, Verbal memory
알츠하이머병(Alzheimer's disease, AD) 환자의 담화 이해 능력 은 일상생활에서의 기능적인 의사소통 능력과 밀접한 관련이 있으 며, 이러한 이유로 관련 연구가 활발히 진행되고 있다. 이와 관련된 연구결과를 종합하면 $\mathrm{AD}$ 로 인한 담화 이해 능력의 손상은 $\mathrm{AD}$ 초 기부터 나타나는 것으로 알려져 있다(Chapman et al., 2002; Choi \& Choi, 2013; Hudon et al., 2006; Orange, Lubinski, \& Higginbotham, 1996; Welland, Lubinski, \& Higginbotham, 2002). 구어적 담화 이해 능력을 평가하기 위하여 가장 많이 사용되는 과제는 이 야기를 듣고 질문에 답하는 이야기 이해 과제이다. 이야기 이해 과
제는 실생활에서 사용되는 구어적 담화 상황을 잘 반영할 뿐 아니 라 사건과 상황을 담고 있어 다른 담화 과제에 비해 내용을 이해하 고 기억하기 용이하다(Lezak, Howieson, \& Loring, 2004). 따라서 $\mathrm{AD}$ 환자를 포함한 신경학적 언어장애군의 담화 이해 능력을 평가 하기 위한 검사로 가장 널리 사용되는 Discourse Comprehension Test (Brookshire \& Nicholas, 1993)의 경우 200 단어 정도의 이야기 이해 과제로 구성되어 있으며, 뇌손상환자의 담화 이해 능력을 평 가하기 위해 고안된 독일어판 Story Comprehension Task (SCT; Ferstl, Walther, Guthke, \& von Cramon, 2005) 역시 이야기 이해 
과제로 구성되어 있다. 이러한 이야기 이해 능력을 평가하기 위한 질문으로는 청각적으로 제시된 이야기 내용에 대한 예-아니오의 재인(recognition) 문항이 가장 일반적으로 사용되고 있다(Brookshire \& Nicholas, 1984). 그러나 재인 문항을 통한 담화 이해 능력의 평가는 제한점을 가진다. 우선 일상생활의 의사소통 상황에서는 의문사를 포함한 다양한 유형의 질문을 주고받기 때문에(Park \& Choi, 2011), 재인 문항만으로는 실제적인 의사소통 능력을 평가하 는 데 한계가 있다. 다음으로 예-아니오 질문의 경우 $50 \%$ 의 우연적 정답 확률을 가지므로 이야기 이해 능력의 차이를 민감하게 반영 하기에는 한계가 있다(Welland et al., 2002). 이러한 이유로 최근에 는 담화 이해 능력을 평가하기 위해 담화 내용에 대한 의문사 질문 에 간단히 답하는 회상(recall) 문항이 사용되고 있다(Choi \& Choi, 2013; Choi, 2014). 국내 연구로 Choi와 Choi (2013)는 회상 문항을 사용하여 경도인지장애(mild cognitive impairment, $\mathrm{MCI}$ )와 $\mathrm{AD}$ 환자의 이야기 이해 능력을 살펴보았는데, 그 결과 일반 노인, $\mathrm{MCI}$, $\mathrm{AD}$ 환자의 순으로 이야기 이해 점수가 높은 것으로 나타났다. 그러 나 이 연구의 경우 각 집단별 피험자 수가 11 명으로 제한적이며, $\mathrm{MCI}$ 환자의 선정 기준이 CDR (Clinical Dementia Rating; Morris, 1993 ) 기억 항목의 점수가 0.5인 경우로 되어있어 $\mathrm{AD}$ 로 전이될 가 능성이 높은 기억상실형 $\mathrm{MCI}$ (amnestic $\mathrm{MCI}, \mathrm{aMCI}$ ) 환자로 국한 되어있지 않는 등의 한계점을 가지고 있다. 따라서 보다 많은 피험 자와 $\mathrm{AD}$ 로 진행될 가능성이 높은 $\mathrm{aMCI}$ 환자만을 대상으로 정상 적인 노화, $\mathrm{aMCI}, \mathrm{AD}$ 의 진행과정 상의 이야기 이해 능력의 변화를 확인할 수 있는 후속연구가 필요하다.

담화 이해 능력은 다양한 인지기능과 관련이 있는 것으로 알려 져 있다. 이러한 담화 이해의 처리 과정과 관련하여 Robertson 등 (2000)은 기능적 뇌영상 연구를 진행하였는데, 그들에 따르면 좌반 구의 활성화를 특징적으로 보이는 단어나 문장 수준의 이해와 달 리 담화를 듣고 이해하는 동안에는 우반구와 전두엽의 활성화가 두드러지게 나타나며, 이는 담화 이해가 언어 이해 능력을 초월한 고차원적인 인지기능을 요구하는 과제임을 보여준다. 그 중에서도 이야기를 듣고 이해하는 능력은 장단기 기억 및 작업기억을 포함한 통합적 기억 능력과 상관이 있으며, 특히 언어기억(verbal memory) 은 담화 이해와 밀접한 관련이 있는 것으로 알려져 있다(Trabasso \& Magliano, 1996). 이와 관련하여 좌반구, 우반구손상환자 및 외 상성 뇌손상환자를 대상으로 Discourse Comprehension Test (Brookshire \& Nicholas, 1993)와 기억 능력의 상관을 살펴본 Ferstl 등(2005) 은 Discourse Comprehension Test의 예-아니오의 재인 문항 총점은 Wechsler Memory Scale-Revised (Wechsler, 1987)의 Logical Memory 및 California Verbal Learning Test (Delis, Kramer, Kaplan, \&
Obler, 1987)의 즉각회상 검사 점수와 유의한 정적상관을 보였다고 보고하였다. 언어기억의 손상은 $\mathrm{MCI}$ 및 $\mathrm{AD}$ 환자들에게서 특징적 으로 나타나며, 언어기억 검사는 $\mathrm{AD}$ 뿐 아니라 $\mathrm{MCI}$ 환자를 정상 고 령자로부터 민감하게 변별해주는 것으로 알려져 있다(Arnáiz \& Almkvist, 2003; Christensen, Hadzi-Pavlovic, \& Jacomb, 1991). 그 중에서도 California Verbal Learning Test-II (Delis, Kramer, Kaplan, \& Ober, 2000)와 같이 단어 목록을 기억하는 언어기억 검사 의 경우 Wechsler Memory Scale-III (Wechsler, 1997)의 Logical Memory 검사보다도 $\mathrm{MCI}$ 를 민감하게 검출해내는 것으로 알려져 있다(Rabin et al., 2009). 이와 더불어 많은 연구자들은 $\mathrm{AD}$ 환자의 언어 이해력 손상이 작업기억 능력의 손상과 깊은 관련이 있음을 보고하였다(MacDonald, Almor, Henderson, Kempler, \& Andersen, 2001; Rochon, Waters, \& Caplan, 1994). 예를 들어, 발화의 마지 막 단어를 기억하는 listening span과제와 Discourse Comprehension Test를 사용하여 $\mathrm{AD}$ 환자의 작업기억과 이야기 이해 능력 사 이의 상관을 연구한 Welland 등(2002)의 연구에서는 .80 의 높은 정 적상관이 나타났다. 그러나 앞에서도 설명했듯이 예-아니오의 재 인 문항을 사용한 이야기 이해 과제는 실생활에서의 기능적인 담 화 이해 상황을 제대로 반영하지 못한다는 제한점을 가진다. 이러 한 제한점을 극복하기 위해 Choi (2014)는 이야기를 듣고 사실적 이해와 추론을 포함한 의문사 질문에 대답하는 회상 과제를 사용 하여 일반 노인을 대상으로 노화로 인한 담화 이해 능력의 저하와 작업기억 및 언어기억 간의 관련성을 살펴보았다. 그의 연구에서는 담화 이해 능력을 살펴보기 위하여 이야기 이해 과제를 사용하였 으며, 작업기억 능력을 평가하기 위해서 숫자외우기 검사(Kang, Chin, \& Na, 2002)를, 언어기억을 평가하기 위해서 서울언어학습검 사(Seoul Verbal Learning Test, SVLT; Kang \& Na, 2003)를 사용하 였다. 그 결과 이야기 이해 점수는 숫자 바로 따라 외우기 점수와는 유의한 상관이 나타나지 않았지만, 숫자 거꾸로 따라 외우기 점수 및 SVLT의 모든 하위 점수에서 유의한 정적상관을 보이는 것으로 나타났다. 이러한 결과는 일반 노인의 담화 이해 능력은 작업 기억 및 언어기억과 관련이 있음을 시사한다. 그러나 담화 이해 결함과 함께 언어기억의 저하를 특징으로 하는 $\mathrm{aMCI}$ 및 $\mathrm{AD}$ 환자의 담화 이해 능력과 언어기억 사이의 관련성을 살펴본 연구는 부족한 실정 이다. 따라서 본 연구는 일반 노인, aMCI, 초기 $\mathrm{AD}$ (early stage of Alzheimer's disease, EAD) 환자를 대상으로 정상적인 노화, aMCI, $\mathrm{EAD}$ 의 진행과정 상의 이야기 이해 능력의 변화를 확인하고, 이러 한 이야기 이해 능력과 작업기억 및 언어기억과의 관련성을 살펴보 는 것을 목적으로 하였다. 


\section{연구 방법}

\section{연구 대상}

본 연구에서는 일반 노인 30명, $\mathrm{aMCI}$ 환자 30 명, $\mathrm{EAD}$ 환자 30명, 총 90명을 연구 대상으로 하였다. 각 집단의 구체적인 선정 기준은 다음과 같다. 우선 비교 집단으로서의 일반 노인은 (1) 한국판 간이 정신상태검사(Korean version of Mini-Mental State Examination, K-MMSE; Kang, 2006) 점수가 -1.0 SD 이상으로 (2) 본인이나 가족 의 보고에 의해 인지기능에 영향을 미치는 신경학적인 질환의 경험 이 없고, (3) 지시 따르기와 시· 청각 능력을 보유하고 있으며, (4) $\mathrm{CDR}$ (Morris, 1993)의 총점이 0인 경우로 하였다. 다음으로 $\mathrm{aMCI}$ 환자는 정신과 전문의에 의해 Petersen 등(2001)의 진단기준에 따 라 $\mathrm{aMCI}$ 로 진단받은 $\mathrm{CDR}$ 총점 .5의 환자로, 구체적으로는 (1) 주 관적인 기억장애를 호소하고, (2) K-MMSE 점수가 -1.0 SD 이상으 로 일반적인 인지기능을 유지하고 있으며, (3) Barthel Index (Mahoney, 1965) 20점으로 일상생활 활동(activities of daily living) 능 력이 정상이고, (4) Korean version of the Consortium to Establish a Registry for Alzheimer's Disease Assessment Packet (CERADK; Lee et al., 2002)의 단어목록회상 검사, 단어목록재인 검사, 구성 회상 검사 중 하나 이상의 수행이 - $1.5 \mathrm{SD}$ 이하로 객관적인 기억력 손상이 나타나지만, (5) 치매의 진단기준에 부합하지 않는 대상으 로 하였다. 마지막으로 $\mathrm{EAD}$ 환자의 선정 기준은 정신과 전문의에 의해 National Institute of Neurological and Communicative Disorders and Stroke and Alzheimer's Disease and Related Disorders Association (NINCDS-ADRDA; McKhann et al., 1984)의 진단 기 준에 따라 $\mathrm{AD}$ 로 진단받은 환자로 $\mathrm{CDR}$ 의 총점이 .5 이거나 1 인 경 우로 하였다.

각 집단별 연구 대상자의 연령, 교육 연수 및 K-MMSE 점수의 기 술통계 결과는 Table 1에 제시하였다. 또한, 세 집단의 연령, 교육 연 수 및 K-MMSE 점수에 차이가 있는지 알아보기 위하여 일원분산 분석을 실시한 결과 연령 $(F=2.434, p>.05)$ 과 교육 연수 $(F=2.101$, $p>.05)$ 는 집단에 따른 차이가 유의하지 않았으나, K-MMSE 점수

Table 1. Descriptive statistics of participants

\begin{tabular}{lccc}
\hline & $H E(N=30)$ & $a M C l ~(N=30)$ & EAD (N=30) \\
\hline Sex (male:female) & $15: 15$ & $15: 15$ & $15: 15$ \\
Age (yr) & $73.50 \pm 5.87(65-68)$ & $71.17 \pm 4.24(65-79)$ & $73.60 \pm 4.21(67-83)$ \\
Education (yr) & $10.07 \pm 3.42(4-16)$ & $9.33 \pm 3.85(1-16)$ & $8.17 \pm 3.57(2-16)$ \\
K-MMSE & $27.30 \pm 1.51(24-30)$ & $26.17 \pm 1.51(24-28)$ & $22.73 \pm 2.77(18-24)$ \\
\hline
\end{tabular}

Values are presented as number or mean \pm SD (range).

$\mathrm{HE}=$ healthy elderly; $\mathrm{aMCl}=$ amnestic mild cognitive impairment; $\mathrm{EAD}=$ early stage of Alzheimer's disease; K-MMSE = Korean version of Mini-Mental State Examination.
는 집단 간 차이가 유의한 것으로 나타났다 $(F=41.650, p<.001) . \mathrm{K}-$ MMSE 점수의 사후분석 결과 일반 노인과 $\mathrm{aMCI}$ 집단 사이에는 유의한 차이가 없었으나, $\mathrm{aMCI}$ 와 $\mathrm{EAD}$ 집단, 일반 노인과 $\mathrm{EAD}$ 집 단의차이는 유의한 것으로 나타났다.

\section{연구 과제}

이야기 이해 과제

본 연구에서는 Choi (2014)에서 사용한 이야기 이해 과제의 이야 기와 질문을 사용하였다. 이 이야기 과제는 노년층에게 친숙한 두 개의 에피소드로 구성되어 있다. 이야기 이해 능력을 평가하기 위 한 질문은 이야기의 내용과 관련된 질문에 간단히 대답하는 회상 문항으로 질문 유형은 이야기에 제시된 사실적 정보의 이해, 이야 기 안에서의 내용을 연결하여 통합적으로 추론하는 텍스트 연결 추론, 청자의 배경지식을 바탕으로 이야기 내용을 해석하는 빠진 정보 추론으로 구성되어 있다. 각각의 유형에 따른 질문은 이야기 당 4 문항씩 12 문항, 총 24 개의 문항으로 구성되어 있으며, 채점 기 준은 적절한 대답 2점, 이야기에 제시되어 있지 않으나 동의어와 같 이 불완전하지만 적절하다고 판단된 대답은 1 점, 부적절한 대답은 0점을 부여하며, 만점은 48 점이다.

\section{작업기억 검사}

작업기억 검사로는 Kang 등(2002)에 의해 개발된 숫자외우기 검 사(Digit Span Test)를 사용하였다. 본 검사는 3-9개의 숫자를 듣고 바로 따라 외우는 숫자 바로 따라 외우기(Digit Span-forward)와 2-8개의 숫자를 듣고 거꾸로 따라 외우는 숫자 거꾸로 따라 외우기 (Digit Span-backward)로 구성되어 있다. 숫자 바로 따라 외우기는 9점, 숫자 거꾸로 따라 외우기는 8점 만점이다.

\section{언어기억 검사}

언어기억을 평가하기 위하여 Kang과 $\mathrm{Na}$ (2003)에 의해 개발된 서울언어학습검사(SVLT)를 사용하였다. SVLT는 12 개의 단어를 불러주고 바로 회상하게 하는 즉각회상(immediate recalls) 검사 3 회, 즉각회상 검사 시행 20 분 후 생각나는 단어를 말하도록 하는 지 연회상(delayed recalls) 검사 및 재인(recognition) 검사로 구성되어 있다. 즉각회상은 36 점, 지연회상은 12 점, 재인은 정반응 (true positive)과 정부정(true negative)의 합인 24점 만점이다.

\section{연구 절차}

모든 검사는 연구자와 대상자가 일대일로 조용한 장소에서 시행 하였다. 대상자에게 과제에 대해 설명한 후 충분히 이해했다고 여겨 
Table 2. The performances of story comprehension, working memory and verbal memory test in the three groups

\begin{tabular}{lccccc}
\hline Task & $\mathrm{HE}$ & $\mathrm{aMCl}$ & $\mathrm{EAD}$ & $\mathrm{F}$ & $\mathrm{Post}$ hoc \\
\hline Story comprehension & $34.93(4.21)$ & $31.80(3.56)$ & $25.33(6.52)$ & $29.570^{* *}$ & $\mathrm{HE}>\mathrm{aMCl}>\mathrm{EAD}$ \\
Digit span & & & & \\
Forward & $6.07(1.66)$ & $5.40(1.28)$ & $4.97(1.22)$ & $4.713^{*}$ & $\mathrm{HE}=\mathrm{aMCl}>\mathrm{EAD}$ \\
Backward & $3.87(1.50)$ & $3.13(.90)$ & $2.97(.99)$ & $5.075^{* *}$ & $\mathrm{HE}>\mathrm{aMCl}>\mathrm{EAD}$ \\
SVIT & & & & \\
Immediate recall & $17.87(4.57)$ & $15.63(4.00)$ & $12.83(4.47)$ & $10.069^{* *}$ & $\mathrm{HE}=\mathrm{aMCl}>\mathrm{EAD}$ \\
Delayed recall & $5.93(2.30)$ & $4.10(1.52)$ & $2.10(2.19)$ & $26.705^{* *}$ & $\mathrm{HE}>\mathrm{aMCl}>\mathrm{EAD}$ \\
Recognition & $19.57(2.49)$ & $18.57(2.22)$ & $17.20(3.12)$ & $6.608^{* *}$ & $\mathrm{HE}=\mathrm{aMCl}>\mathrm{EAD}$ \\
\hline
\end{tabular}

Values are presented as mean (SD).

$\mathrm{HE}=$ healthy elderly; $\mathrm{aMCl}=$ amnestic mild cognitive impairment; $\mathrm{EAD}=$ early stage of Alzheimer's disease; SVLT=Seoul Verbal Learning Test.

${ }^{*} p<.05,{ }^{* *} p<.01$.

Table 3. The correlation coefficient among the story comprehension, working memory and verbal memory scores in healthy elderly

\begin{tabular}{|c|c|c|c|c|c|c|}
\hline & Story comprehension & DF & $\mathrm{DB}$ & Immediate recalls & Delayed recalls & Recognition score \\
\hline Story comprehension & 1 & & & & & \\
\hline DF & .173 & 1 & & & & \\
\hline $\mathrm{DB}$ & $.391^{*}$ & $.612^{* *}$ & 1 & & & \\
\hline Immediate recalls & $.528^{* *}$ & .488 & $.660^{* *}$ & 1 & & \\
\hline Delayed recalls & $.565^{* *}$ & .263 & $.525^{* *}$ & $.713^{* *}$ & 1 & \\
\hline Recognition score & $.366^{*}$ & .116 & $.370^{*}$ & $.547^{* *}$ & $.472^{* *}$ & 1 \\
\hline
\end{tabular}

$\mathrm{DF}=$ Digit Span forward; DB= Digit Span backward.

${ }^{*} p<.05,{ }^{* *} p<.01$.

진 상태에서 본 검사를 실시하였다. 이야기 이해 과제는 Choi (2014) 의 절차를 따라 관련 삽화를 보여주며 이야기를 들려주고 이야기 의 내용에 대해 질문을 하였다. 대상자의 반응은 모두 녹음하고 전 사하였다. 숫자외우기 검사와SVLT는 표준화된 실시 절차를 따랐다.

\section{통계 처리}

본 연구의 통계분석은 IBM SPSS Statistics ver. 22 프로그램을 사 용하였다. 우선 일반 노인, aMCI, EAD 집단의 이야기 이해 과제 수 행력 및 언어기억 검사 결과의 집단에 따른 차이가 있는지 알아보 기 위하여 일원분산분석(ANOVA)을 실시하고, 집단 간의 차이가 있는 경우 Tukey 방법을 사용하여 사후분석을 실시하였다. 다음으 로 세 집단의 이야기 이해 능력과 언어기억 검사와의 상관을 알아 보기 위하여 집단별로 Pearson 상관분석을 실시하였다. 유의수준 은.05로 하였다.

\section{연구 결과}

\section{집단에 따른 이야기 이해와 작업기억 및 언어기억 검사 결과}

일반 노인, $\mathrm{aMCI}, \mathrm{EAD}$ 집단의 이야기 이해 과제와 작업기억 및 언어기억 검사 수행의 기술통계치를 Table 2에, 각 과제별 수행률

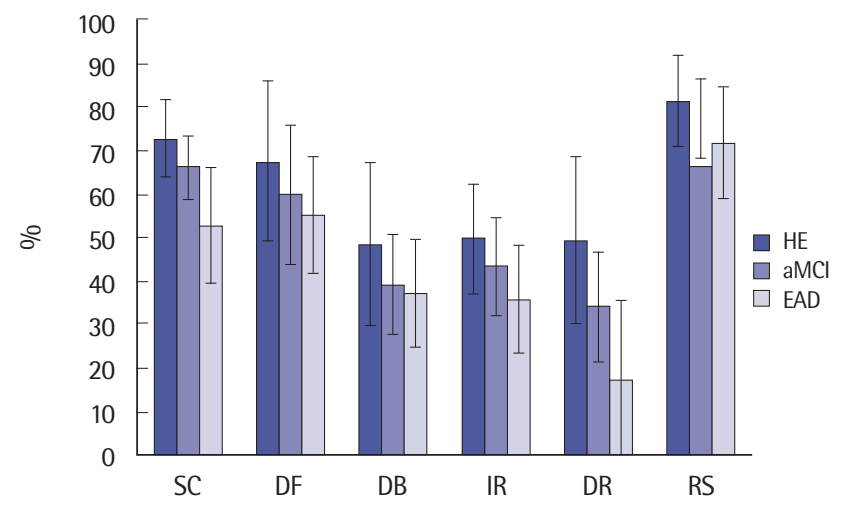

Figure 1. Percentage (\%) of story comprehension, working memory and verbal memory scores by group. $\mathrm{SC}=$ story comprehension; $\mathrm{HE}=$ healthy elderly; $\mathrm{aMCl}$ =amnestic mild cognitive impairment; $E A D=$ early stage of Alzheimer's disease; $\mathrm{DF}=$ Digit Span forward; $\mathrm{DB}=$ Digit Span backward; $\mathrm{IR}=$ immediate recall; $\mathrm{DR}=$ delayed recall; $\mathrm{RS}=$ recognition score.

(\%)을 Figure 1에 제시하였다. 결과를 정리하면, 이야기 이해 과제 와 작업기억 및 언어기억 검사 모든 하위 항목 점수에서 집단 간의 수행 차이가 유의한 것으로 나타났다. 사후분석 결과 이야기 이해 과제, 숫자 거꾸로 따라 외우기, SVLT의 지연회상 수행의 경우 일 반 노인, $\mathrm{aMCI}, \mathrm{EAD}$ 집단 간의 차이가 모두 유의하였으나, 숫자 바 로 따라 외우기, SVLT의 즉각회상 및 재인 수행의 경우 일반 노인 
Table 4. The correlation coefficient among the story comprehension, working memory and verbal memory scores in aMCl

\begin{tabular}{|c|c|c|c|c|c|c|}
\hline & Story comprehension & DF & $\mathrm{DB}$ & Immediate recalls & Delayed recalls & Recognition score \\
\hline Story comprehension & 1 & & & & & \\
\hline DF & .071 & 1 & & & & \\
\hline $\mathrm{DB}$ & .289 & $.523^{* *}$ & 1 & & & \\
\hline Immediate recalls & .329 & .232 & $.387^{*}$ & 1 & & \\
\hline Delayed recalls & $.515^{* *}$ & .228 & .293 & $.602^{* *}$ & 1 & \\
\hline Recognition score & .289 & .185 & .323 & $.706^{* *}$ & $.678^{* *}$ & 1 \\
\hline
\end{tabular}

$\mathrm{DF}=$ Digit Span forward; $\mathrm{DB}=$ Digit Span backward.

${ }^{*} p<.05,{ }^{* *} p<.01$.

Table 5. The correlation coefficient among the story comprehension, working memory and verbal memory scores in EAD

\begin{tabular}{|c|c|c|c|c|c|c|}
\hline & Story comprehension & DF & $\mathrm{DB}$ & Immediate recalls & Delayed recalls & Recognition score \\
\hline Story comprehension & 1 & & & & & \\
\hline DF & .275 & 1 & & & & \\
\hline $\mathrm{DB}$ & $.647^{* *}$ & .339 & 1 & & & \\
\hline Immediate recalls & $.548^{* *}$ & $.373^{*}$ & $.493^{* *}$ & 1 & & \\
\hline Delayed recalls & $.433^{*}$ & .273 & .349 & $.581^{* *}$ & 1 & \\
\hline Recognition score & $.393^{*}$ & .283 & .334 & $.752^{* *}$ & $.780^{* *}$ & 1 \\
\hline
\end{tabular}

$\mathrm{DF}=$ Digit Span forward; $\mathrm{DB}=$ Digit Span backward.

${ }^{*} p<.05,{ }^{* *} p<.01$.

과 $\mathrm{aMCI}$ 집단 간의 차이는 유의하지 않으며, $\mathrm{aMCI}$ 와 $\mathrm{EAD}$ 집단 간 의 차이는 유의한 것으로 나타났다.

\section{집단에 따른 이야기 이해와 작업기억 및 언어기억 검사 사이의 상관}

일반 노인, $\mathrm{aMCI}, \mathrm{EAD}$ 집단의 이야기 이해 과제와 작업기억 및 언어기억 검사 수행 사이의 상관분석 결과를 Tables 3-5에 제시하 였다. 결과를 종합하면, 일반 노인과 EAD 집단의 경우 이야기 이해 과제와 숫자 거꾸로 따라 외우기, SVLT의 모든 하위 점수와 유의한 정적상관이 있는 것으로 나타났으나, aMCI의 경우 이야기 이해 과 제의 수행은 SVLT의 지연회상 점수와만 유의한 정적상관이 있는 것으로 나타났다.

\section{논의 및 결론}

본 연구는 일반 노인, $\mathrm{aMCI}, \mathrm{EAD}$ 환자를 대상으로 이야기 이해 과제와 작업기억 및 언어기억 검사를 사용하여, 정상적인 노화, $\mathrm{aMCI}, \mathrm{AD}$ 의 진행과정 상의 이야기 이해 능력의 변화를 확인하고, 이러한 이야기 이해 능력과 작업기억 및 언어기억의 관련성을 살펴 보는 것을 목적으로 하였다.

연구 결과를 종합하면, 첫째 집단에 따른 이야기 이해 및 작업기 억 및 언어기억 검사의 모든 항목에서 $\mathrm{EAD}$ 환자의 수행은 일반 노
인과 $\mathrm{aMCI}$ 환자에 비해 유의한 저하를 보였다. 그러나 $\mathrm{aMCI}$ 환자 의 경우 이야기 이해 수행, 숫자 거꾸로 따라 외우기, SVLT의 지연 회상에서만 일반 노인에 비해 유의하게 낮은 수행을 보였고, 나머 지 항목에서는 일반 노인과 수행 차이가 유의하지 않았다. 우선 이 야기 이해를 포함한 모든 과제에서 $\mathrm{EAD}$ 환자의 수행이 일반 노인 이나 $\mathrm{aMCI}$ 환자에 비해 유의하게 저하되어 있다는 것은 기존의 연 구들과 맥락을 같이 한다. 이야기 이해 능력과 관련하여 예를 들자 면, Welland 등(2002)은 재인 과제를 사용한 이야기 이해 수행에서 $\mathrm{EAD}$ 환자는 일반 노인에 비해 유의하게 낮은 이야기 이해 능력을 보였다고 보고하였으며, 회상 과제를 사용한 Choi와 Choi (2013)의 연구에서 역시 $\mathrm{AD}$ 환자의 이야기 이해 능력은 일반 노인에 비해 저 하되어 있는 것으로 나타났다. 이러한 결과는 $\mathrm{EAD}$ 환자의 경우 비 록 질환의 초기 단계일지라도 이미 일상생활 활동에 제한을 가져 올 만큼의 언어 및 인지기능 저하를 가진 대상자들이므로 다양한 인지기능을 요구하는 통합적인 과제로 알려져 있는 이야기 이해 과 제(Ferstl et al., 2005; Paul, 2007)에서 수행 저하가 확인된 것으로 생각해볼 수 있다. 다음으로 기억 능력의 저하와 관련해서도 대부 분의 연구들은 $\mathrm{EAD}$ 환자의 기억 능력이 일반 고령자나 $\mathrm{aMCI}$ 환자 들에 비해 저하되어 있다는 것에는 이견이 없다(Petersen, Smith, Ivnik, Kokmen, \& Tangalos, 1994). 따라서 본 연구에서 사용한 작 업기억과 언어기억 검사에서 $\mathrm{EAD}$ 환자의 기억 능력의 저하가 확인 된 것으로 생각해 볼 수 있다. 이렇듯 $\mathrm{EAD}$ 환자들의 이야기 이해 능 
력 및 기억 능력의 저하에 대해서는 논란의 여지가 없는 것과 달리 $\mathrm{aMCI}$ 환자들의 일부 언어기억의 수행은 일반 노인과의 차이가 유 의하지 않은 것으로 나타났다. 우선, 작업기억 중 숫자 거꾸로 따라 외우기에서, 언어기억 중 SVLT의 지연회상에서만 일반 노인과 유 의한 차이를 보인 것에 대해서는 $\mathrm{aMCI}$ 집단의 특성과 관련이 있을 수 있다. 본 연구의 대상인 aMCI환자들은 Petersen 등(2001)의 기 준에 따라 객관적인 기억 검사 중 하나 이상의 항목에서 규준에 비 해 -1.5 SD 이하의 수행을 보인 환자들이었다. 따라서 이들 중에는 단일영역(single domain) aMCI와 다발영역(multiple domains) $\mathrm{aMCI}$ 가 혼재되어 있을 가능성이 있다(Petersen, 2004). 이렇듯 $\mathrm{aMCI}$ 는 기억 이외의 다양한 인지기능 저하를 동반하고 있는 임상 적으로 이질적인(heterogeneous) 집단이다. 따라서 $\mathrm{aMCI}$ 의 경우 기억 과제의 종류와 난이도에 따라 저하 양상이 다르게 나타날 수 있다(Price et al., 2010). 본 연구에서 사용되었던 작업기억 검사인 숫자외우기 검사의 경우 숫자 바로 따라 외우기 검사는 작업기억 중 시연을 통한 단기 저장 능력을 강조하는 음운고리(phonological loop)의 영향이 큰 반면, 숫자 거꾸로 따라 외우기는 음운고리 이외 에 저장된 언어를 조정하고, 통합하여 처리하는 ‘중앙집행기'의 역 할이 강조된다(Hester, Kinsella, \& Ong, 2004). 따라서 보다 통합적 인 작업기억을 요구하는 숫자 거꾸로 따라 외우기 검사가 $\mathrm{aMCI}$ 환 자들의 미세한 작업기억 능력의 저하를 민감하게 검출해 낼 수 있 던 것으로 보인다. 다음으로 언어기억 검사 중 SVLT의 즉각회상 및 재인에서 일반 노인과의 차이가 유의하지 않았던 $\mathrm{aMCI}$ 환자가 지 연회상에서만 유의한 차이를 보인 것은 즉각회상이나 재인에 비해 지연회상 검사가 $\mathrm{MCI}$ 나 $\mathrm{AD}$ 환자를 일반 노인으로부터 잘 변별해 준다고 보고한 기존의 연구결과들(Baek, Kim, \& Kim, 2012; Rabin et al., 2009)과 일맥상통한다. 이러한 결과는 일반 노인과 K-MMSE 점수에서 유의한 차이를 보이지 않을 정도로 비교적 아주 초기의 $\mathrm{aMCI}$ 환자들이 본 연구에 많이 포함된 점을 감안한다면 작업기억 과 언어기억 중 지연회상의 저하가 $\mathrm{aMCI}$ 환자들을 변별해낼 수 있 는 유용한 임상적인 척도가 됨을 의미한다. 또한, 이러한 아주 초기 의 $\mathrm{aMCI}$ 환자의 경우에도 이야기 이해 과제에서 일반 노인에 비해 유의하게 낮은 수행을 보였다는 것은 이야기 이해 과제 역시 초기 $\mathrm{aMCI}$ 환자들의 언어 및 인지기능의 미세한 저하를 민감히 검출해 내는 검사라는 점을 시사한다.

다음으로 본 연구의 두 번째 목적은 일반 노인, $\mathrm{aMCI}, \mathrm{EAD}$ 집단 에 따른 이야기 이해 능력과 작업기억 및 언어기억 간의 상관을 알 아보는 것이었다. 결과를 살펴보면, 일반 노인과 $\mathrm{EAD}$ 집단이 동일 하게 이야기 이해 과제와 작업기억 중 숫자 거꾸로 따라 외우기와 언어기억의 모든 하위 항목의 수행과 유의한 정적상관이 있는 것으
로 나타났다. 그러나 $\mathrm{aMCI}$ 의 경우 이야기 이해 과제의 수행은 언어 기억 중 SVLT의 지연회상 항목의 수행과만 유의한 정적상관이 있 는 것으로 나타났다. 이와 관련하여 구체적으로 살펴보면 첫째, 이 야기 이해 능력과 작업기억과의 상관분석에서 세 집단 모두 숫자 바로 따라 외우기 검사의 수행은 이야기 이해 능력과 유의한 상관 이 나타나지 않았지만, 일반 노인 및 $\mathrm{EAD}$ 집단은 숫자 거꾸로 따라 외우기와 이야기 이해 능력 사이에 유의한 정적상관이 나타났다. Daneman과 Carpenter (1980)는 작업기억과 언어 이해 능력과의 관련성을 설명하면서, 저장 기능을 강조하는 음운고리의 역할을 평가하는 작업기억 과제보다는 저장과 처리를 동시에 강조하는 중 앙집행기의 역할을 평가하는 작업기억 과제가 언어 이해 능력을 예 측하는 데에 더 민감하다고 하였다. 그들이 사용한 작업기억 과제 는 읽기 폭(reading span) 과제나 마지막 단어 회상(final word recall) 과제로, 본 연구의 숫자외우기 과제에 비해 다소 복잡한 과제 이기 때문에 직접적인 비교는 불가능하지만 본 연구에서도 이야기 이해 능력과 중앙집행기의 역할을 평가하는 숫자 거꾸로 따라 외우 기의 상관이 유의하게 높게 나타났다. 반면에 뇌손상환자를 대상 으로 이야기 이해 능력과 인지기능과의 관련성을 살펴본 Ferstl 등 (2005)의 연구에서는 이야기 이해 능력과 작업기억 사이에는 유의 한 상관이 나타나지 않아 본 연구의 결과와 다소 상이하다. 그러나 그들의 연구는 뇌졸중으로 인한 좌반구, 우반구손상환자 및 외상 성 뇌손상환자가 혼재되어 있어 다양한 인지기능 장애를 함께 가 진 이질적인 집단의 이야기 이해 능력과 작업기억 사이의 상관을 분석하였기 때문에 다소 다른 결과가 나온 것으로 여겨진다. 또한, 그들의 연구는 예-아니오의 재인 문항으로 이야기 이해 능력을 평 가하였는데, 회상 문항은 재인 문항에 비해 저장된 정보를 처리하 여 산출하기까지 더 고차원적인 작업기억의 역할이 요구된다(Carpenter, Miyake, \& Just, 1994). 따라서 사용한 문항의 종류에 따라 이야기 이해와작업기억과의 관련성이 다르게 나타날 수 있다는 점 도 고려해야 할 것이다. 한 가지 흥미로운 결과는 일반 노인과 EAD 집단의 경우 이야기 이해 능력과 숫자 거꾸로 따라 외우기의 상관 이 .39, .65로 비교적 높게 나타났지만, aMCI의 경우. 29 로 통계적으 로 유의하지 않은 상관을 보였다. 이러한 다소 역설적인 결과는 작 업기억의 저장 및 처리 기능의 손상과 관련하여 생각해 볼 수 있다. 일반 노인의 경우 담화 이해 능력의 저하는 주로 저장 능력의 손상 과 그로 인한 처리 기능의 할당량 제한과 관련이 있다(Choi, 2014; Fischer \& Glanzer, 1986). 이러한 저장 능력의 제한은 EAD환자에 게서 더 극명하게 나타나며, 처리 기능의 인지적 할당 용량의 제한 역시 더욱 두드러질 가능성이 있다. 그러나 $\mathrm{aMCI}$ 환자의 경우 일반 노인과 비교하여 평균적인 저장 능력의 제한이 나타나지만, 이들의 
기억장애 양상은 다소 이질적이다. 이와 관련하여 Jeong, Kim과 Lee (2012)는 단일영역 aMCI를 저장장애(retention-deficit)군과 인 출장애(retrieval-deficit)군으로 분류하였을 때 $1 / 3$ 정도는 정상적 인 재인 능력을 가진 인출장애군으로 분류된다고 보고하였다. 본 연구의 $\mathrm{aMCI}$ 환자들의 언어기억 능력을 살펴보면 SVLT의 즉각회 상 및 재인 점수에서는 일반 노인과 유의한 차이가 나타나지 않았 지만 지연회상에서는 일반 노인에 비해 수행이 저하되었으며, SVLT의 지연회상 수행만 이야기 이해 능력과 유의한 상관을 보였 다. 이러한 결과는 $\mathrm{aMCI}$ 환자들의 기억 능력의 제한은 저장장애보 다는 인출장애에 의한 것임을 의미하며, $\mathrm{aMCI}$ 의 이질적인 기억 능 력의 제한으로 인해 이야기 이해 능력과작업기억과의 상관이 상대 적으로 낮아질 가능성을 생각해볼 수 있다. 또한, $\mathrm{aMCI}$ 환자들의 경우 기억 이외의 미세하지만 다양한 인지기능장애를 동반하기 때 문에 이러한 영향으로 이야기 이해 능력과 기억 항목들 간의 상관 이 다른 집단에 비해 다소 낮아진 것으로 해석할 수 있다.

마지막으로 일반 노인과 $\mathrm{EAD}$ 집단은 이야기 이해 과제와 언어기 억 중 SVLT의 모든 하위 점수와 유의한 정적상관이 있는 것으로 나타났다. 일반 노인의 이야기 이해 능력과 언어기억의 상관을 연 구한 Choi (2014)에 따르면 SVLT와 같은 단어 목록 학습 검사의 경 우 복잡한 언어, 인지적 처리과정을 요구하기 때문에 이러한 언어기 억의 수행이 높으면 역시 통합적인 언어, 인지적 처리과정을 요구하 는 이야기 이해에서 좋은 수행을 보인다. 이러한 결과는 이야기 이 해 능력과 단어 목록 학습 검사의 수행 사이의 관련성에 있어서 정 상적인 노화와 $\mathrm{AD}$ 로 인한 결과에 유사성이 있음을 시사한다.

본 연구는 일반 노인, $\mathrm{aMCI}, \mathrm{EAD}$ 환자를 대상으로 이야기 이해 능력과 언어기억 능력을 평가하여 정상적인 노화와 $\mathrm{AD}$ 의 단계적 이야기 이해 능력을 살펴보고, $\mathrm{AD}$ 진행에 따른 이야기 이해 능력 과 작업기억 및 언어기억 간의 상관을 비교하여 분석하였다는 데에 의의를 가진다. 그러나 질문 유형에 따른 차이 및 오류 분석이 면밀 하게 이루어지지 못한 점, 이야기 이해 능력과 기억 이외의 다양한 인지기능 사이의 상관을 살펴보지 못한 점 등이 아쉬움으로 남는 다. 앞으로는 $\mathrm{aMCI}, \mathrm{EAD}$ 환자를 대상으로 이야기 이해 능력의 면 밀한 분석과 더불어 이러한 이야기 이해 능력과 다양한 인지기능 과 관련성을 살펴보는 연구가 진행되기를 기대한다.

\section{REFERENCES}

Arnáiz, E., \& Almkvist, O. (2003). Neuropsychological features of mild cognitive impairment and preclinical Alzheimer's disease. Acta Neurologica Scandinavica, 107(s179), 34-41.
Baek, M. J., Kim, H. J., \& Kim, S. (2012). Comparison between the story recall test and the word-list learning test in Korean patients with mild cognitive impairment and early stage of Alzheimer's disease. Journal of Clinical and Experimental Neuropsychology, 34, 396-404.

Brookshire, R. H., \& Nicholas, L. E. (1984). Comprehension of directly and indirectly stated main ideas and details in discourse by brain-damaged and non-brain-damaged listeners. Brain and Language, 21, 21-36.

Brookshire, R. H., \& Nicholas, L. E. (1993). Discourse Comprehension Test. Tucson, AZ: Communication Skill Builders.

Carpenter, P. A., Miyake, A., \& Just, M. A. (1994). Working memory constraints in comprehension: evidence from individual differences, aphasia, and aging. In M. A. Gernsbacher (Ed.), Handbook of psycholinguistics, (pp. 1075-1122). San Diego, CA: Academic Press.

Chapman, S. B., Zientz, J., Weiner, M., Rosenberg, R., Frawley, W., \& Burns, M. H. (2002). Discourse changes in early Alzheimer disease, mild cognitive impairment, and normal aging. Alzheimer Disease \& Associated Disorders, 16, 177-186.

Choi, C. S., \& Choi, H. (2013). Story comprehension ability in patients with MCI and DAT. Journal of Speech-Language and Hearing Disorders, 22, 159-180.

Choi, H. (2014). Verbal working memory and verbal memory's relationship to discourse comprehension in healthy elderly. Communication Sciences \& Disorders, 19, 513-522.

Christensen, H., Hadzi-Pavlovic, D., \& Jacomb, P. (1991). The psychometric differentiation of dementia from normal aging: a meta-analysis. Psychological Assessment: A Journal of Consulting and Clinical Psychology, 3, 147155.

Daneman, M., \& Carpenter, P. A. (1980). Individual differences in working memory and reading. Journal of Verbal Learning and Verbal Behavior, 19, 450-466.

Delis, D. C., Kramer, J. H., Kaplan, E., \& Obler, B. A. (1987). California Verbal Learning Test (CVLT): adult version. San Antonio, TX: Psychological Corporation.

Delis, D. C., Kramer, J. H., Kaplan, E., \& Obler, B. A. (2000). California Verbal Learning Test-second edition (CVLT-II). San Antonio, TX: Psychological Corporation.

Ferstl, E. C., Walther, K., Guthke, T., \& von Cramon, D. Y. (2005). Assessment of story comprehension deficits after brain damage. Journal of Clinical and Experimental Neuropsychology, 27, 367-384.

Fischer, B., \& Glanzer, M. (1986). Short-term storage and the processing of 
cohesion during reading. Quarterly Journal of Experimental Psychology, $38,431-460$.

Hester, R. L., Kinsella, G. J., \& Ong, B. (2004). Effect of age on forward and backward span tasks. Journal of the International Neuropsychological Society, 10, 475-481.

Hudon, C., Belleville, S., Souchay, C., Gély-Nargeot, M. C., Chertkow, H., \& Gauthier, S. (2006). Memory for gist and detail information in Alzheimer's disease and mild cognitive impairment. Neuropsychology, 20, 566-577.

Jeong, E. H., Kim, H. Y., \& Lee, J. H. (2012). Can we further divide amnestic mild cognitive impairment based on the pattern of memory deficit? A preliminary study. Dementia and Neurocognitive Disorders, 11, 18-24.

Kang, Y. (2006). A normative study of the Korean-Mini Mental State Examination (K-MMSE) in the elderly. Korean Journal of Psychology: General, 25, 1-12.

Kang, Y., \& Na, D. L. (2003). Seoul Neuropsychological Screening Battery. Seoul: Human Brain Research \& Consulting Co.

Kang, Y., Chin, J., \& Na, D. L. (2002). A normative study of the Digit Span Test for the elderly. Korean Journal of Clinical Psychology, 21, 911-922.

Lee, J. H., Lee, K. U., Lee, D. Y., Kim, K. W., Jhoo, J. H., Kim, J. H., ... \& Woo, J. I. (2002). Development of the Korean version of the Consortium to Establish a Registry for Alzheimer's Disease Assessment Packet (CERAD-K) clinical and neuropsychological assessment batteries. Journals of Gerontology Series B: Psychological Sciences and Social Sciences, 57, 47-53.

Lezak, M. D., Howieson, D. B., \& Loring, D. W. (2004). Neuropsychological assessment (4th ed.). New York: Oxford University Press.

MacDonald, M. C., Almor, A., Henderson, V. W., Kempler, D., \& Andersen, E. S. (2001). Assessing working memory and language comprehension in Alzheimer's disease. Brain and Language, 78, 17-42.

Mahoney, F. I. (1965). Functional evaluation: the Barthel index. Maryland State Medical Journal, 14, 61-65.

McKhann, G., Drachman, D., Folstein, M., Katzman, R., Price, D., \& Stadlan, E. M. (1984). Clinical diagnosis of Alzheimer's disease Report of the NINCDS-ADRDA Work Group under the auspices of Department of Health and Human Services Task Force on Alzheimer's Disease. Neurology, 34, 939-944.

Morris, J. C. (1993). The Clinical Dementia Rating (CDR): current version and scoring rules. Neurology, 43, 2412-2414.

Orange, J. B., Lubinski, R. B., \& Higginbotham, D. J. (1996). Conversational repair by individuals with dementia of the Alzheimer's type. Journal of Speech, Language, and Hearing Research, 39, 881-895.

Park, J., \& Choi, Y. (2011). Comprehension of wh-questions in Broca’s aphasia. Journal of Rehabilitation Research, 15, 55-74.

Paul, R. (2007). Language disorders from infancy through adolescence: assessment e intervention (3rd ed.). St. Louis, MO: Mosby.

Petersen, R. C. (2004). Mild cognitive impairment as a diagnostic entity. Journal of Internal Medicine, 256, 183-194.

Petersen, R. C., Doody, R., Kurz, A., Mohs, R. C., Morris, J. C., Rabins, P. V., ... \& Winblad, B. (2001). Current concepts in mild cognitive impairment. Archives of Neurology, 58, 1985-1992.

Petersen, R. C., Smith, G. E., Ivnik, R. J., Kokmen, E., \& Tangalos, E. G. (1994). Memory function in very early Alzheimer's disease. Neurology, 44, 867867.

Price, S. E., Kinsella, G. J., Ong, B., Mullaly, E., Phillips, M., Pangnadasa-Fox, L., ... \& Storey, E. (2010). Learning and memory in amnestic mild cognitive impairment: contribution of working memory. Journal of the International Neuropsychological Society, 16, 342-351.

Rabin, L. A., Paré, N., Saykin, A. J., Brown, M. J., Wishart, H. A., Flashman, L. A., ... \& Santulli, R. B. (2009). Differential memory test sensitivity for diagnosing amnestic mild cognitive impairment and predicting conversion to Alzheimer's disease. Aging, Neuropsychology, and Cognition, 16, 357-376.

Robertson, D. A., Gernsbacher, M. A., Guidotti, S. J., Robertson, R. R., Irwin, W., Mock, B. J., ... \& Campana, M. E. (2000). Functional neuroanatomy of the cognitive process of mapping during discourse comprehension. Psychological Science, 11, 255-260.

Rochon, E., Waters, G. S., \& Caplan, D. (1994). Sentence comprehension in patients with Alzheimer's disease. Brain and Language, 46, 329-349.

Trabasso, T., \& Magliano, J. P. (1996). Conscious understanding during comprehension. Discourse Processes, 21, 255-287.

Wechsler, D. (1987). Wechsler Memory Scale-revised (WMS-R). San Antonio, TX: Psychological Corporation.

Wechsler, D. (1997). Wechsler Memory Scale-third edition (WMS-III). San Antonio, TX: Psychological Corporation.

Welland, R. J., Lubinski, R., \& Higginbotham, D. J. (2002). Discourse comprehension test performance of elders with dementia of the Alzheimer type. Journal of Speech, Language, and Hearing Research, 45, 1175-1187. 


\section{국문초록}

\section{기억상실형 경도인지장애와 알츠하이머병 환자의 이야기 이해 능력과 작업기억 및 언어기억의 상관} 최현주

나사렛대학교 언어치료학과

배경 및 목적: $\mathrm{AD}$ 로 인한 담화 이해 능력의 저하는 질환의 초기부터 나타나는 것으로 알려져 있다. 본 연구에서는 이야기 이해 과제와 작업기억 및 언어기억 검사를 사용하여 $\mathrm{AD}$ 로 인한 이야기 이해 능력의 변화를 확인하고, 이들의 상관을 알아보는 것을 목적으로 하였 다. 방법: 본 연구는 일반 노인 30 명, $\mathrm{aMCI}$ 환자 30 명, $\mathrm{EAD}$ 환자 30 명을 대상으로 하였다. 담화 이해 과제는 회상 질문에 답하는 이야기 이해 과제를 사용하였으며, 작업기억 과제로는 숫자외우기 검사(Digit Span Test)를, 언어기억 과제로는 서울언어학습검사(SVLT)를 사 용하였다. 결과: 이야기 이해 과제 수행은 일반 노인, $\mathrm{aMCI}, \mathrm{EAD}$ 환자 순으로 높았으며, 모든 과제에서 집단 간 차이가 유의한 것으로 나타났다. 둘째, 일반 노인과 $\mathrm{EAD}$ 집단의 경우 이야기 이해 과제와 집행기능 과제 중 숫자 거꾸로 따라 외우기, 언어기억의 모든 하위 점 수와 유의한 정적상관이 있는 것으로 나타났으나, $\mathrm{aMCI}$ 의 경우 이야기 이해 과제의 수행은 언어기억 중 SVLT의 지연회상 항목의 수행 과만 유의한 정적상관이 있는 것으로 나타났다. 논의 및 결론: 본 연구 결과로부터 초기의 $\mathrm{aMCI}$ 단계에서도 이야기 이해 능력의 저하 가 나타나며, 이러한 이야기 이해 능력과 언어기억 간의 상관은 $\mathrm{AD}$ 진행과정에서 다소 상이하게 나타남을 알 수 있다.

핵심어: 기억상실형 경도인지장애, 알츠하이머병, 이야기 이해, 작업기억, 언어기억

본 연구는 2016년도 나사렛대학교 교내연구비 지원에 의한 연구임.

\section{참고문헌}

강연욱(2006). K-MMSE (Korean-Mini Mental State Examination)의 노인 규준 연구. 한국심리학회지: 일반, 25, 1-12.

강연욱, 나덕렬(2003). 서울신경심리검사(Seoul Neuropsychological Screening Battery). 서울: 휴브알엔씨.

강연욱, 진주희, 나덕렬(2002). 숫자 외우기 검사(Digit Span Test)의 노인 규준 연구. 한국심리학회지: 임상, 21, 911-922.

박정은, 최예린(2011). 브로카 실어증 환자의 의문문 이해. 재활복지, $15,55-74$.

정은혜, 김희영, 이재홍(2012). 기억상실형 경도인지장애를 기억장애의 양상에 따라 세분화할 수 있는가? 예비연구. 대한치매학회지, 11, 18-24.

최창선, 최현주(2013). 경도인지장애와 알츠하이머형 치매 환자의 이야기 이해 특성. 언어치료연구, 22, 159-180.

최현주(2014). 고령자의 담화 이해 능력과 구어 작업기억 및 언어기억과의 상관. 언어청각장애연구, 19, 513-522. 